\title{
UNIVERSAL NORMS AND CONFLICTING VALUES
}

MICHAEL J. SELGELID

\begin{abstract}
While UNESCO's Universal Draft Declaration on Bioethics and Human Rights highlights appropriate ethical values, its principles are stated in absolute terms and conflict with one another. The Draft Declaration fails to sufficiently address the possibility of conflict between principles, and it provides no real guidance on how to strike a balance between them in cases where conflict occurs. The document's inadequate treatment of conflicting values is revealed by examination of cases where principles aimed at the promotion of autonomy and liberty conflict with those aimed at benefit maximization and harm minimization. I argue that liberty (and autonomy) may be less important in the context of health care than in other contexts, and I conclude by suggesting specific ways in which some of UNESCO's principles should be revised in order to better address the reality of conflicting values.
\end{abstract}

\section{INTRODUCTION}

In many ways the United Nations Educational, Scientific and Cultural Organization's (UNESCO) Universal Draft Declaration on Bioethics and Human Rights (UDDBHR $)^{1}$ reads like a list of standard bioethics principles. ${ }^{2}$ Its various articles require (among other things) the promotion of human rights, fundamental freedoms, autonomy, justice, equality, maximization of benefit,

1 United Nations Educational, Scientific and Cultural Organization (UNESCO). 2005. Universal Draft Declaration on Bioethics and Human Rights. SHS/ EST/05/CONF.204/3REV. Paris, 24 June 2005. UNESCO.

${ }^{2}$ I thank two anonymous reviewers for providing valuable comments on an earlier version of this paper.

(C) Blackwell Publishing Ltd. 2005, 9600 Garsington Road, Oxford OX4 2DQ, UK and 350 Main Street, Malden, MA 02148, USA. 
minimization of harm, informed consent, privacy and confidentiality. Though these are laudable goals, the statement that they should each be promoted provides little direction to decision makers looking for, or likely to listen to, ethical guidelines. In cases where all of these things would be promoted by one decision, then this would already be the obvious decision of choice for any decision maker with enough ethical conscience or motivation to be looking to UNESCO for guidance.

Given that these goods do not always all travel together, however, we invariably must choose between them. The promotion of one person's autonomy can conflict with the autonomy or well being of others - and it can also often conflict with equality. The reality and prevalence of this kind of conflict means that it would be impossible to follow all of UNESCO's principles, which are often stated in absolute terms without mention of limitation, exception, or conflict. ${ }^{3}$ The reality of conflict was admitted in an earlier draft of the UNESCO declaration's final section on Operation of the Principles and Declaration, which stated in Article 29, 'Where there is conflict between the principles this should be resolved by balancing all those principles that are appropriate and relevant in the circumstances. ${ }^{4}$ Beyond admitting conflict, virtually nothing was said about how conflict should be resolved via the balancing of principles. In the UDDBHR explicit admission of conflict between principles is dropped, and 'balance' is never mentioned.

Despite the nonexistence of a universally acceptable, well developed, systematic ethical framework for striking a balance between conflicting goods, should not something be said about when autonomy should prevail over equality, benefit maximization, or

\footnotetext{
3 The main treatment of limitation appears in Article 27 of the Final Provisions Section which states, 'If the application of the principles in this Declaration are to be limited, it should be by law, including laws in the interests of public safety, for the investigation, detection and prosecution of criminal offences, for the protection of public health or for the protection of the rights and freedoms of others. Any such law needs to be consistent with international human rights law.' UNESCO, op. cit. note 1. This says little about (1) how to choose between conflicting principles in cases where the law does not do so, and (2) how to decide what the law should be in cases where that is the issue in question. I would also argue that this article should be revised to include protection of the well being of others as a potential justification of the laws in question.

${ }^{4}$ United Nations Educational, Scientific and Cultural Organization (UNESCO). 2005. Preliminary Draft Declaration on Universal Norms on Bioethics. SHS/EST/CIB-EXTR/05/CONF.202/2. Paris. UNESCO. Available at: http:// portal.unesco.org/shs/en/file_download.php/10d16a8d802caebf882673e4443 950fdPreliminary_Draft_EN.pdf [accessed 7 July 2005].
} 
harm minimization? Most would, upon reflection anyway, deny that any one of these things should always be given priority over the others (in cases of conflict) regardless of the extent to which the others are threatened. UNESCO's declaration should say more about how trade-offs should be made between conflicting goods by saying more about what is special about health care. The extent to which health care distribution involves externalities, for example, provides grounds for treating health care as a public good ${ }^{5}-$ and thus for sometimes sacrificing liberty for the common good in cases of conflict. UNESCO should explicitly recognize this special feature of health care and the grounds it provides for compromising at least certain forms of liberty.

In what follows, I will provide examples that illustrate how UNESCO's treatment of conflicting values is inadequate. Focusing on cases where autonomy conflicts with benefit maximization, harm minimization, or the common good, I will argue that the question of how to strike a balance between liberty and other goods is partly answered by recognition of what is ethically important about liberty to begin with. In public goods contexts (such as health care) where liberty threatens promotion of the greater good, the goal of promoting liberty should be given less weight than would otherwise be the case. I conclude by making suggestions about how UNESCO's principles should be rewritten to better account for conflicting values.

\section{CONFLICT}

Articles 5 and 6 of UNESCO's UDDBHR both appeal to the importance of individual autonomy or liberty. The former says that:

[t]he autonomy of persons to make decisions, while taking responsibility for those decisions and respecting the autonomy of others, is to be respected. ${ }^{6}$

The latter says that:

[a]ny preventive, diagnostic and therapeutic medical intervention is only to be carried out with the prior, free and informed consent of the person concerned, based on adequate information. ${ }^{7}$

${ }^{5}$ R. Smith et al. eds. 2003. Global Public Goods for Health. New York. Oxford University Press. Note that UNESCO does not mention the concept "public good' anywhere in the UDDBHR.

${ }^{6}$ UNESCO, op. cit. note 1 . Article 5.

${ }^{7}$ Ibid. Article 6. 
Both of these principles, however, can conflict with a more utilitarian principle included in the document: i.e. Article 4 which says that:

[i]n applying and advancing scientific knowledge and medical practice, direct and indirect benefits to patients, research participants and other affected individuals should be maximized and any possible harm to such individuals should be minimized. ${ }^{8}$

Article 5 apparently grants freedom to those who would use genetic technologies to enhance their quality of life or the quality of life of their offspring. The practice of genetic enhancement by the rich, however, could (in conflict with Article 4) harm others (who should presumably also be considered 'affected individuals') who would end up being competitively disadvantaged because they cannot afford enhancement oriented technologies. The advancement of enhancement orientated genetic technologies would likely have further disutility (again in conflict with Article 4) if the profitability of developing them draws industry resources away from more fruitful technological directions (such as antibiotic and vaccine development) ${ }^{9}$ The fact that this kind of concern is not merely academic is revealed by the, now infamous, $10 / 90$ divide. $^{10}$

Article 6 grants freedom to refuse diagnosis of, treatment for, or vaccination against infectious diseases. Again, one individual's autonomy can conflict with well being of others (in violation of Article 4, again assuming that these others are 'affected individuals'). If individuals are granted freedom to refuse diagnosis of, treatment for, or vaccination against, epidemic disease, then this can threaten harm to others who might be infected and harm to society as a whole. The public good of herd immunity, for example, could be jeopardized if the freedom to refuse vaccination were widely respected. ${ }^{11}$ While the promotion of utility in the

8 Ibid. Article 4.

9 M.J. Selgelid. 2002. Societal Decision Making and the New Eugenics. In the Grey Series of the European Academy (Europaische Akademie) for the Study of Consequences of Scientific and Technological Advance, Bad NeuenahrAhrweiler GmbH, Germany, Nr. 30, available at http://c108.susanis.de/pages/ publikationen/graue_reihe/30.pdf [accessed 5 July 2005].

10 Global Forum for Health Research. 2002. The 10/90 Report on Health Research 2001-2002. Geneva, Switzerland. Available at: http://www. globalforumhealth.org/site/002_What\%20we\%20do/005_Publications/ 001_10\%2090\%20reports.php [accessed 11 July 2005].

11 A. Dawson. Risk Perceptions and Ethical Public Health Policy. Forthcoming in Poiesis and Praxis: International Journal of Ethics of Science and Technology Assessment. 
way of public health (required by Article 4) can conflict with autonomy (as protected by Articles 5 and 6), we sometimes give priority to the former over the latter. This is evidenced, first, by current tuberculosis policy in countries (such as the US) where those who refuse treatment are held in confinement and, second, by the coercive measures that were (arguably rightly) employed in one of medicine's greatest successes - i.e. the smallpox eradication campaign. The idea that informed consent to medical treatment is sometimes outweighed by other considerations is, third, also apparently embodied by the World Health Organization's (WHO) current polio eradication program. In India, for example,

the policy of deliberate non-disclosure of information about risks [from oral polio vaccine has] the clear intention of maintaining high levels of participation. For example, while it has been known for a long time that [oral polio vaccine] can cause [vaccine associated paralytic poliomyelitis], doctors in India are advised not to inform the public of this fact. ${ }^{12}$

\section{LIBERTY}

Faced with such conflicts, which should be prioritized, individual liberty or utility? This question is partly addressed through recognition of the reasons why liberty is considered important in the first place. Both free-market advocates and Millian liberals argue that liberty is at least partly important because the respecting of liberty (or autonomy) usually promotes the greater good in the way of utility (or efficiency). ${ }^{13}$ In the context of health care, however, there is no reason to assume that liberty will always promote utility - and this is because health is like a public good insofar as externalities result with its distribution. This is demonstrated in the examples above. In the case of genetic enhancement, third parties who cannot afford enhancement are harmed in the way of competitive disadvantage. In the case of refusal of treatment or vaccination, third parties are harmed by increased risk of infection. In cases where third parties may be (directly or indirectly) harmed by the promotion of individual liberty, there

12 Y. Paul \& A. Dawson. Some Ethical Issues Arising from Polio Eradication Programmes in India. Forthcoming in Bioethics 2005; 19,4.

13 A. Sen. 1999. Development as Freedom. New York. Anchor Books; J.S. Mill. 1859. On Liberty. Indianapolis. Hackett, reprint 1979. In what follows, I use 'utility' and 'efficiency' interchangeably. I am also often using 'autonomy' and 'liberty' interchangeably (or as proxies for one another). 
is no reason to expect that the liberty will promote utility ${ }^{14}$ (as assumed by standard theoretical justifications of liberty). Because the importance of liberty is partly (though not entirely) based on the assumption that the respect of liberty will promote utility, part (though not all) of its importance falls away in the context of health care (because health care distribution involves externalities, and there are no good theoretical or empirical reasons for thinking that liberty promotes utility in the context of goods involving externalities). The fact that health is like a public good is thus one reason - in addition to standard egalitarian and human rights reasons - for treating it as something special (in comparison with other goods or commodities) when making decisions about its distribution.

\section{REVISION}

I do not want to deny that liberty (or autonomy) is important for its own sake or imply that its ethical importance reduces to its instrumental value in the promotion of utility or the common good. In this brief commentary, I similarly do not aim to resolve all (or even most) of the difficult questions about how trade-offs should be made in situations involving conflict between the promotion of things such as liberty and utility (or equality). My more modest aim is to illustrate the kinds of cases where liberty or autonomy - despite their intrinsic, noninstrumental importance - might sometimes conflict with, and potentially be outweighed by, other social goods.

Without taking a stand on the profoundly difficult philosophical question of exactly how (intrinsically) important liberty and autonomy are in comparison with other goods embodied by its document, UNESCO could make progress towards confronting conflicting values via minor revision of the UDDBHR. Article 5, for example, should be rewritten to say that:

the autonomy of persons to make decisions, while taking responsibility for those decisions and respecting the autonomy and well being of others, is to be respected.

Article 6(a) should likewise be revised to say that:

any preventive, diagnostic and therapeutic medical intervention is only to be carried out with the prior, free and informed consent of the person concerned, based on adequate

14 A. Buchanan. 1985. Ethics, Efficiency, and the Market. Totowa, NJ. Rowman \& Littlefield. 
UNIVERSAL NORMS AND CONFLICTING VALUES 273

information - with the possible exception of emergencies or other situations where other individuals or public health would be seriously threatened by strict adherence to such requirements. ${ }^{15}$

While still leaving open the question of how one person's liberty or autonomy should be weighed against the well being of others - and the question of how the promotion of public health should be weighed against the importance of informed consent to diagnosis and treatment - such revisions would at least make more directly explicit the kinds of conflicts that decision makers are likely to be faced with. Such revisions would also provide suggestions about how to make trade-offs when conflict does arise. The purpose of the UNESCO document is perhaps to draw attention to fundamentally important bioethical values, rather than to resolve deep philosophical questions about conflicts between them. Be that as it may, UNESCO should avoid stating principles in absolute (and inconsistent) terms.

Michael J. Selgelid, PhD

Sesquicentenary Lecturer in Bioethics

Centre for Values, Ethics and the Law in Medicine; and

Unit for History and Philosophy of Science

University of Sydney

NSW 2006

Australia

selgelid@med.usyd.edu.au

15 As pointed out by an anonymous reviewer, similar qualifications should be added to (at least) Articles 3, 4 and 10.

๑) Blackwell Publishing Ltd. 2005 